\title{
PENELITIAN KORELASI PLASTICIZER DOP DAN FILI.ER \\ SERBUK KAYU MERANTI UNTUK ACUAN SEPATU
}

Oleh : Irene Sri Sukaeni. Susilawati, M. Sri Wahyuni

\section{ABSTRACT}

This research is to find out correlation of using DOP plasticier and Shorea Parvifolis Dyer wood flour filler to physical properties of PVC compound for shoe lasting. PVC compound is made from PVC resin added by other ingredients as plasticizer, stabilizer, lubricant and filler. Ingredient used in this research is DOP, Epoxy oil, $\mathrm{BaCdZn}_{\mathrm{n}}$, Stearic acid, $\mathrm{CaCO}_{3}$ filler and wood flour by variation of DOP and filler percentage. PVC compound produced is tested its physical properties for hardness, impact sirength and tensil strength. Data prove that there is correlation between the physical test and percentage of DOP and wood flour filler fulfilling multiple linier regression for hardness and mutliple quadratis regression for impact strength and tensile sirength.

\section{INTISARI}

Penelitian ini bertujuan untuk mengetahui korelasi penggunaan plasticier DOP dan filler sebuk kayu meranti terhadap sifat-sifat fisika kompon PVC untuk acuan sepatu. Kompon PVC dibuat dari bahan baku resin PVC dengan ditambah ingredient lain yang berfungsi sebagai plasticizer, stbailizer, lubricant dan filler. Pada penelitian ini ingredient yang dipergunakan adalah: DOP, Epoxy oil, $\mathrm{BaCdZn}$, asam stearat serta filler $\mathrm{CaCO}_{3}$ dan sebuk kayu meranti dengan variasi persentase DOP dan filler serbuk kayu. Kompon PVC yang dihasilkan diuji sifat fisikanya untuk kekerasan, ketahanan pukul dan kekuatan tarik. Data uji fisika menunjukkan adanya korelasi antara uji fisika tersebut dengan persentase DOP dan filler serbuk kayu dengan memenuhi persamaan regresi linier multipel untuk kekerasan dan regresi kuadratis multipel untuk uji ketahanan pukul takik dan kekuatan tarik.

\section{PENDAHULUAN}

Dalam proses pembuatan sepatu, acuan digunakan sebagai cetakan yang akan menentukan bentuk akhir sepatu dan juga menentukan keserasian serta keenakan pakai. Acuan sepatu dapat dibuat dari kayu, aluminium dan plastik. Bahan baku untuk acuan sepatu dari plastik umumnya dari jenis PE (Laporan penelitian-tentang acuan sepatu dari plastik, tahun1983), oleh karena itu pada penelitian ini dicoba untuk membuat kompon plastik dari PVC 


\section{untuk acuan sepatu.}

Untuk memperoleh sifat-sifat seperti yang diinginkan, PVC sebagai baban baku harus ditambah dengan bahan-bahan pembantu lain. Penambahan bahan pembantu plasticizer dan filler akan memberi sifat kekerasan dan kełahanan pukul. Plasticizer yang umum digunakan adalah DOP (Dioctyl Phtalat). Dalain komponding DOP berfungsi untuk menambah sifat kelenturan, kelunakan dan kemuluran tetapi disamping itu akan mengurangi daya regang. ${ }^{5}$ Sedangkan penambahan filler disamping memperbaiki sifat fisika juga menurunkan biaya produksi. Jenis filler yang dipilih tergantung pada sifat produk yang dikehendaki. Filler serbuk kayu akan mempengaruhi warna produk akhir. Jenis pohon Pine, Sponce, Fir akan memberikan warna-warna terang, sedang jenis pohon Maple, Birch dan Oak akan memberikan warnawarna gelap. ${ }^{5}$ Serbuk kayu untuk filler dibuat dari kulit pohon kayu yang digiling sehingga menjadi partikel-partikel dengan ukuran tertentu, persyaratan kadar air antara 2 - $3 \%$.

Filler serbuk kayu akan menjadikan produk akhir bersifat tahan yang baik. ${ }^{2}$ ) Dalam penelitian ini dipilih filler dari serbuk kayu meranti karena bahannya mudah didapat.

Untuk mendapatkan gabungan sifat-sifat fisis yang optimal perlu dilakukan penelitian korelasi penggunaan plasticizer DOP dan filler serbuk kayu meranti sebagai dasar untuk pembuatan acuan sepatu dari PVC

\section{MATERI DAN METODE PENELITIAN}

\section{Materi Penelitian}

Pada penelitian ini dilakukan korelasi plasticizer dan filler. Sebagai plasticizer dipakai DOP dengan variasi : $20 \%, 25 \%, 30 \%, 35 \%, 40 \%$ dan $45 \%$. Sedangkan sebagai filler dipakai serbuk kayu meranti dengan variasi : $20 \%, 25 \%, 30 \%, 35 \%$ dan $40 \%$.

Kompisi kompon acuan sepatu:

$\begin{array}{llc}\text { PVC } & : & 100 \% \\ \text { DOP } & : \text { bervariasi }(20 \%, 25 \%, 30 \%, 35 \%, 40 \% \text { dan } 45 \%) \\ \text { Epoxy } & : & 5 \% \\ \text { BaCdZn } & : & 3,5 \% \\ \text { Asam stearat } & : & 0,75 \% \\ \text { DaCO } 3 & : & 10 \% \\ \text { Serbuk kayu } & : \text { bervariasi }(20 \%, 25 \%, 30 \%, 35 \%, \text { dan } 40 \%)\end{array}$

2. Metode Penelitian

Dibuat komponen dengan komposisi seperti tersebut diatas. Bahan-bahan setelah ditimbang lalu dicampur dalam mixer sampai rata dan digiling dengan alat two roll mill dengan suhu $\pm 50^{\circ} \mathrm{C}$.
Untuk membuat contoh uji, kompon tersebut dibuat bentuk slab dengan tebal $3 \mathrm{~mm}$ menggunakan hydraulic press dengan suhu $170^{\circ} \mathrm{C}$, tekanan $150 \mathrm{~kg} / \mathrm{cm}^{2}$ dan waktu 10 menit.

Hasil penelitian diuji sifat-sifat fistkanya untuk kekerasan, ketahanan pukul. dan kekuatan tarik. Kekerasan diuji dengan Hardness tester shore D, ketahanan pukul dengan lzodimpact tester dan kekuatan tarik dengan Tensile strength tester. Data hasil uji dianalisa secara statistik dengan menggunakan metode multipel regresi.

\section{DATA HASIL UJI}

Tabel 1.

Hasil Uji Kekerasan Shore D

\begin{tabular}{|c|c|c|c|c|c|c|}
\hline $\begin{array}{l}\text { DOP } \\
\text { Filler }\end{array}$ & 20 & 25 & 30 & 35 & 40 & 45 \\
\hline \multirow{4}{*}{20} & 65 & 60 & 59 & 52 & 44 & 40 \\
\hline & 65 & 60 & 60 & 52 & 45 & 40 \\
\hline & 65 & 60 & 60 & 52 & 45 & 42 \\
\hline & 65 & 60 & 59,6 & 52 & 44,66 & 40,66 \\
\hline \multirow{4}{*}{25} & 67 & 62 & 60 & 53 & 47 & 43 \\
\hline & 66 & 62 & 60 & 53 & 47 & 43 \\
\hline & 66 & 62 & 60 & 54 & 47 & 43 \\
\hline & 66,33 & 62 & 60 & 53,33 & 47 & 43 \\
\hline \multirow{4}{*}{30} & 68 & 64 & 60 & 54 & 48 & 43 \\
\hline & 69 & 64 & 60 & 54 & 48 & 43 \\
\hline & 70 & 64 & 61 & 55 & 47 & 44 \\
\hline & 69 & 64 & 60,33 & 54,33 & 47,66 & 43,33 \\
\hline \multirow{4}{*}{35} & 70 & 64 & 60 & 55 & 49 & 44 \\
\hline & 70 & 64 & 61 & 55 & 48 & 44 \\
\hline & 70 & 65 & 61 & 55 & 50 & 45 \\
\hline & 70 & 64,33 & 60,66 & 55 & 49 & 45,33 \\
\hline
\end{tabular}

Vol IX No. 18 Tahun 1993/1994 


\begin{tabular}{|c|c|c|c|c|c|c|}
\hline \multirow{4}{*}{40} & 70 & 65 & 64 & 56 & so & 46 \\
\hline & 70 & 63 & 62 & 56 & so & 46 \\
\hline & 72 & 65 & 62 & 58 & 30 & 46 \\
\hline & 70,66 & 65 & 62,66 & 62,66 & 30 & 46 \\
\hline \multicolumn{7}{|c|}{ Tabel 2 Hasil Uja Ketałanan Pukul Kgem/can } \\
\hline $\begin{array}{l}\text { DOP } \\
\text { Fuler }\end{array}$ & 20 & 25 & 30 & 35 & 40 & 45 \\
\hline \multirow{4}{*}{20} & 2,49 & 4,18 & 4,01 & 5,94 & 21,27 & 32,75 \\
\hline & 2,33 & 2866 & 4,10 & 5,93 & 22,18 & 32,01 \\
\hline & 2,48 & 3,44 & 4,19 & 5,96 & 21,24 & 30,88 \\
\hline & 2,43 & 3,44 & 4,10 & 3,95 & 21,24 & 31,88 \\
\hline \multirow{4}{*}{25} & 1,60 & 2,76 & 3,43 & 6,07 & 15,55 & 21,35 \\
\hline & 1,48 & 3,62 & 4,25 & 5,87 & 17,00 & 20,31 \\
\hline & 1,59 & 2,75 & 4,11 & 7,80 & 18,11 & 22,81 \\
\hline & 1,56 & 3,04 & 3,93 & 6,58 & 17,22 & 21,49 \\
\hline \multirow{4}{*}{30} & 2,36 & 3,97 & 4,32 & 7,21 & 15,21 & 26,35 \\
\hline & 2,23 & 3,73 & 5,98 & 6,26 & 14,54 & 26,89 \\
\hline & 2,44 & 3,82 & 5,03 & 4,77 & 14,32 & 28,88 \\
\hline & 2,34 & 3,84 & 5,11 & 8,08 & 14,69 & 27,37 \\
\hline \multirow{4}{*}{35} & 2,81 & 3,18 & 5,22 & 6,07 & 14,80 & 33,87 \\
\hline & 3,10 & 3,18 & 4,51 & 6,03 & 14,42 & 31,41 \\
\hline & 2,75 & 3,39 & 5,33 & 6,07 & 14,22 & 33,91 \\
\hline & 2,89 & 3,25 & 5,02 & 6,06 & 14,48 & 33,06 \\
\hline \multirow{4}{*}{40} & 2,82 & 3,39 & 3,35 & 4,96 & 9,03 & 19,54 \\
\hline & 2,43 & 3,13 & 3,39 & 5,18 & 9,86 & 20,33 \\
\hline & 2,43 & 3,11 & 3,36 & 4,99 & 9,82 & 21,08 \\
\hline & 2,56 & 3,21 & 3,37 & 5,04 & 9,57 & 20,35 \\
\hline
\end{tabular}

Tabel 3. Hasil Uji : Kuat Tarik $\mathrm{Kg} / \mathrm{cm}^{2}$

\begin{tabular}{|c|c|c|c|c|c|c|}
\hline $\begin{array}{l}\text { DOP } \\
\text { Filler }\end{array}$ & 20 & 25 & 30 & 35 & 40 & 45 \\
\hline \multirow{4}{*}{20} & 180,10 & 176,28 & 124,69 & 104,96 & 93,63 & 92,94 \\
\hline & 215,17 & 157,17 & 124,85 & 105,60 & 88,38 & 88,38 \\
\hline & 228,23 & 186,61 & 124,70 & 101,42 & 125,79 & 94,97 \\
\hline & 207,83 & 173,52 & 124,74 & 103,99 & 102,60 & 92,10 \\
\hline \multirow{4}{*}{25} & 178,36 & 145,45 & 113,21 & 100,86 & 79,27 & 76,04 \\
\hline & 182,93 & 146,52 & 114,39 & 101,89 & 76,31 & 79,21 \\
\hline & 185,45 & 125,61 & 116,39 & 104,96 & 77,66 & 73,15 \\
\hline & 182,24 & 139,19 & 114,65 & 102,60 & 77,75 & 76,13 \\
\hline \multirow{4}{*}{30} & 208,33 & 153,59 & 116,91 & 104,56 & 80,77 & 80,13 \\
\hline & 219,48 & 155,64 & 118,50 & 104,25 & 78,58 & 83,65 \\
\hline & 249,40 & 161,50 & 120,65 & 108,27 & 78,91 & 86,87 \\
\hline & 225,74 & 156,91 & 118,69 & 105,69 & 79,42 & 83,55 \\
\hline \multirow{4}{*}{35} & 212,76 & 133,82 & 122,53 & $91 \mathrm{~m} 54$ & 72,96 & 87,56 \\
\hline & 219,45 & 168,47 & 126,67 & 98,60 & 77,99 & 89,60 \\
\hline & 231,32 & 167,86 & 127,45 & 96,96 & 71,21 & 84,23 \\
\hline & 222,17 & 156,72 & 125,55 & 95,70 & 75,05 & 87,13 \\
\hline \multirow{4}{*}{40} & 296,97 & 151,51 & 127,33 & 93,28 & 72,76 & 100,00 \\
\hline & 220,41 & 166,10 & 130,72 & 103,93 & 63,35 & 90,00 \\
\hline & 204,57 & 174,55 & 131,41 & 104,56 & 73,80 & 102,92 \\
\hline & 240,65 & 164,05 & 129,82 & 100,57 & 69,97 & 97,64 \\
\hline
\end{tabular}

HASIL PENELITIAN DAN PEMBAHASAN

Hasil penelitian berupa hasil uji fisika kompon PVC untuk acuan sepatu dengan variasi persentase DOP dan filler serbuk kayu meranti, dapat dilihat pada tabel 1,2 dan 3 . 
Data hasil uji dianalisa secara statistik dengan menggunakan analisa regresi dan hasilnya dapat dilihat pada tabel 4,5 dan 6 .

Tabel 4. Analisa sidik ragam (Anova) regresi multipel untuk kekerasan.

\begin{tabular}{|c|c|c|c|c|c|c|}
\hline \multirow{2}{*}{$\begin{array}{c}\text { Sumber } \\
\text { variasi }\end{array}$} & \multirow{2}{*}{$\mathrm{dk}$} & \multirow{2}{*}{ JK } & \multirow{2}{*}{ RJK } & \multirow{2}{*}{ F hitung } & \multicolumn{2}{|c|}{ F tabel } \\
\hline & & & & & $5 \%$ & $1 \%$ \\
\hline Regresi & 2 & 6900,5760 & 3450,2580 & $2158,9001^{* *}$ & 3,10 & 4,85 \\
\hline $\mathrm{X} 1$ & 1 & 6658,0277 & 6658,0277 & $4165,9540^{* *}$ & 3,95 & 6,93 \\
\hline $\mathrm{X} 2$ & 1 & 242,6787 & 242,6787 & $151,8450^{* *}$ & 3,95 & 6,93 \\
\hline Residual & 87 & 139,0395 & 1,5982 & - & - & - \\
\hline Total & 89 & - & - & - & - & - \\
\hline
\end{tabular}

R multipel

R2

$=0,9901$

$=0,9802$

Persamaan regresi : $\mathrm{Y}=81,9908-1,0072 \mathrm{X} 1+0,2322 \mathrm{X} 2$

Tabel 5. Analisa sidik ragam (Anova) regresi multipel untuk Ketahanan pukul.

\begin{tabular}{|c|c|c|c|c|c|c|}
\hline \multirow{2}{*}{$\begin{array}{c}\text { Sumber } \\
\text { variasi }\end{array}$} & \multirow{2}{*}{ dk } & \multirow{2}{*}{ JK } & \multirow{2}{*}{ RJK } & \multirow{2}{*}{ F hitung } & \multicolumn{2}{|c|}{ F tabel } \\
\hline & & & & & $5 \%$ & $1 \%$ \\
\hline Regresi & 3 & 6959,4302 & 2319,8101 & $292,4001^{* *}$ & 2,71 & 4,01 \\
\hline $\mathrm{X} 1$ & 1 & & & $87,4070^{* *}$ & 3,95 & 6,93 \\
\hline$\left(X_{1}\right)^{2}$ & 1 & & & $166,7300^{* *}$ & 3,95 & 6,93 \\
\hline$X_{1} X^{2}$ & 1 & & & 15,3260 & 3,95 & 6,93 \\
\hline Residual & 86 & 682,2969 & 7,9337 & - & - & - \\
\hline Total & 89 & 7641,7271 & - & - & - & - \\
\hline
\end{tabular}

$\begin{array}{ll}\mathrm{R} \text { multipel } & =0,9543 \\ \mathrm{R} 2 & =0,9107\end{array}$

Persamaan regresi : $\mathrm{Y}=40,3764-2,9325 \mathrm{X} 1+0,0615 \mathrm{X} 2$
Tabel 6. Analisa sidik ragam (Anova) regresi multipel untuk Kekuatan tarik.

\begin{tabular}{l|r|r|r|r|r|r}
\hline \multirow{2}{*}{$\begin{array}{c}\text { Sumber } \\
\text { variasi }\end{array}$} & dk & JK & RJK & F hitung & \multicolumn{2}{|c}{ F tabel } \\
\cline { 5 - 7 } & & & & & $5 \%$ & $1 \%$ \\
\hline Regresi & 4 & 199731,2519 & 49932,8130 & $224,8350^{* *}$ & 2,47 & 4,04 \\
$\mathrm{X}_{12}$ & 1 & & & $123,0900^{* *}$ & 3,95 & 6,93 \\
$\mathrm{X}_{12}$ & 1 & & & $114,6170^{* *}$ & 3,95 & 6,93 \\
$\mathrm{X}_{2}$ & 1 & & & $14,4870^{* *}$ & 3,95 & 6,93 \\
$\mathrm{X}_{1} \mathrm{X}_{2}$ & 1 & & & 12,9950 & 3,95 & 6,93 \\
Residual & 85 & 18877,3537 & 222,0865 & & - & - \\
Total & 89 & 218608,6057 & & - & - & - \\
\hline
\end{tabular}

$\begin{array}{ll}\mathrm{R}^{2} & =0,9136 \\ \mathrm{R} \text { multipel } & =0,9558\end{array}$

Persamaan regresi : $\mathrm{Y}=509,7063-19,999 \mathrm{X}_{1}+0,2697 \mathrm{X}_{12}$

$+0,0517 \times 22-0,0879 \mathrm{X}_{1} \mathrm{X}_{2}$

1. Korelasi antara penambahan filler serbuk kayu meranti dan plasticizer DOP terhadap kekerasan kompon :

Persamaan regresi yang diperoleh dari tabel 4 menunjukkan adanya korelasi antara penambahan filler serbuk kayu meranti dan plasticizer DOP terhadap kekerasan kompon.

$F$ hitung $X_{1}$ dan $X_{2}$ lebih besar dari $F$ tabel, keduanya berpengaruh sangat nyata, tetapi pada $X_{1}$ lebih besar. Hal ini menunjukkan bahwa pengaruh faktor plasticizer DOP $(\mathrm{X} 1)$ lebih besar dari pada pengaruh faktor filler serbuk kayu meranti $\left(\mathrm{X}_{2}\right)$.

Pada kadar plasticizer DOP tetap sedangkan filler serbuk kayu bervariasi naik $5 \%$, maka kekerasan kompon mengalami kenaikan. Hal ini karena sifat filler yang dapat memperbaiki kekerasan. Tetapi pada kadar filler tetap dan plasticizer DOP bervariasi naik $5 \%$, kekerasan kompon cenderung turun, karena kompon menjadi lunak, sesuai dengan sifat plasticizer DOP yang dapat memperbaiki sifat kelenturan kompon. Meskipun pada umumnya penambahan filler akan menambah kekerasan produk, tetapi penambahan filler serbuk kayu sampai dengan $35 \%$ masih menghasilkan produk akhir yang bersifat lentur.

2. Korelasi antara penambahan filler serbuk kayu meranti dan plasticizer

Vol IX No. 18 Tahun 1993/1994 


\section{DOP terhadap pukul takik kompon.}

Persamaan regresi yang diperoleh dari tabel 5 menunjukkan adanya korelasi antara penambahan filler serbuk kayu meranti dan piasticizer DOP terhadap pukul takik kompon. Setiap penambahan filler serbuk kayu meranti sebesar $5 \%$ cenderung menaikan pukul takik kompon. Hal ini karena fungsi DOP sebagai plasticizer menyebabkan kompon menjadi plastis.

Pada kadar plasticizer DOP tetap dan Iller serbuk kayu meranti naik 5\%, iidak terjadi kenaikan atau penurunan yang nyata terhadap hasil uji ketahanan pukul, berarti penambahan filler serbuk kayu tidak begitu berpengaruh pada ketahanan pukul takik.

Setiap kenaikan $5 \%$ kadar plasticizer DOP pada jumlah filer serbuk kayu telap, ketalianan pukul takik mengalami kenaikan cukup besar. Ha! ini menunjukan babwa penambahan plasticier DOP sangat berpengaruh pada ketahanan pukul takik kompon acuan.

3. Korelasi antara penambahan filler serbuk kayu meranti dan plasticizer DOP terhadap kuat tarik kompon.

Persamaan regresi yang diperoleh dari tabel 6 menunjukkan adanya korelasi antara penambahan filler serbuk kayu meranti dan plasticizer DOP terhadap kuat tarik kompon.

Setiap kenaikan 5\% kadar plasticizer DOP pada jumlah filler serbuk kayu meranti tetap, kuat tarik kompon cenderung menurun. Hal ini karena sifat plasticizer DOP yang melunakan kompon. Makin tinggi kadar plasticizer DOP yang digunakan menyebabkan kompon semakin plastis.

\section{KESIMPULAN}

1. Adanya korelasi antara penambahan filler serbuk kayu meranti dan plasticizer DOP terhadap kekerasan, pukul takik dan kuat tarik kompon acuan sepatu.

2. Pengaruh faktor plasticizer DOP terhadap sifat-sifat fisika lebih besar dibandingkan pengaruh faktor filler serbuk kayu meranti.

3. Setiap penambahan filler serbuk kayu meranti sebesar $5 \%$ yang diikuti dengan penambahan plasticizer DOP sebesar $5 \%$ cenderung menurunkan kekerasan, menaikkan pukul takik dan menurunkan kuat tarik kompon acuan sepatu.

4. Titik optimal yang dicapai dari hasil penelitian adalah : Pada perbandingan plasticizer DOP : filler serbuk kayu meranti $=40: 35$ dihasilkan kom- pon dengan kekerasan 49,00 shore D dan ketahanan pukul takik 14,48 $\mathrm{kgcm} / \mathrm{cm}$.

5. Untuk dapat dipakai sebagai kompon acuan, kekerasan harus dinaikkan.

\section{DAFTAR PUSAKA}

1. Ciba Geigy Merienbreg GMBH, Manual of PVC Additive, 1971.

2. Harry S. Kertz, John V. Milewski, Handbook of Fillers and Reinforcements for Plastics, van Nostrand Reinhold Company, New York, 1978.

3. Siti Rochani, Ir. dkk, Laporan Penelitian tentang Acuan Sepatu dari Plastik, BBKKP, 1983.

4. Sudjana, MA. Msc., Teknik Analisis Regresi dan Korelasi Tarsito, Bandung, 1983.

5. Suntoyo, Ir., Experimental Design, Universitas Brawijaya, Malang.

6. Terry A. Richardson, Modern Industrial Plastics, Howard Sams and Co, Inc. Indiana Polis Kansas City, New York, 1974. 